\title{
Registro pelo panicograma de freqüência e intensidade dos ataques de pânico
}

O transtorno do pânico é constituído por diferentes sintomas cuja intensidade pode ser avaliada por medidas objetivas, e a evolução dos pacientes, da mesma forma. Estas devem conter, pelo menos, cinco domínios principais: (1) ataques de pânico, incluindo os incompletos; (2) ansiedade antecipatória; (3) fobias relacionadas ao pânico, incluindo agorafobia e fobias relacionadas a sensações corporais; (4) bemestar/gravidade global da doença; e (5) incapacitações quanto ao trabalho, interações sociais e família. ${ }^{1}$ Para a avaliação desses domínios, podem ser utilizados tanto vários instrumentos em conjunto quanto um instrumento que por si só abranja todos esses aspectos, como o PDSS (Panic Disorder Severity Scale). ${ }^{1-3} \mathrm{O}$ propósito dessa comunicação é descrever o "panicograma", um instrumento simples de monitoramento da freqüência e da intensidade de crises de pânico. $\mathrm{O}$ uso do panicograma possibilita ao paciente especificar os sintomas que constituem seus ataques, a freqüência destes e a evolução do quadro, ao longo do tempo, pelo registro diário por parte do paciente. Em cada espaço da grade, o paciente preenche com um traço o número de vezes em que apresentou o sintoma, referido à esquerda, no dia correspondente do mês citado. Na parte inferior do gráfico, existe um espaço reservado para informar a medicação e a dose usada pelo pacien-

\section{Referências}

1. Ballenger JC, Davidson JRT, Lecrubier Y, Nutt DJ, Baldwin DS, den Boer JA, et al. Consensus statement on panic disorder from the international consensus group on depression and anxiety. J Clin Psychiatry 1998;59(8 suppl):47-54.

2. Shear MK, Maser JD. Standardized assesment for panic disorder research. Arch Gen Psychiatry 1994;51:346-54. te. É preenchido um gráfico por mês ao longo do tratamento, sendo o mesmo levado às consultas para discussão.

Assim, o panicograma possibilita que o próprio paciente monitore seus sintomas e que tenha uma real avaliação da presença e da freqüência de suas crises. Nas mulheres, também possibilita correlação ao ciclo menstrual, se assim interessar. O caráter contínuo de avaliação propicia discutir com o paciente a evolução do quadro com a observação dos gráficos e, assim, avaliar a sua melhora.

O preenchimento do panicograma fica sob o encargo do paciente, que pode, por algum motivo, não o preencher adequadamente ou de forma sincera, o que pode prejudicar uma adequada avaliação. Para minimizar essas limitações do panicograma, sugere-se que o paciente seja adequadamente esclarecido a respeito dos ataques de pânico e sobre os diferentes sintomas e, acima de tudo, seja estimulado para o adequado preenchimento.

\section{Regina Margis \\ Universidade Federal do Rio Grande do Sul (UFRGS)}

Flávio Kapczinski

Departamento de Psiquiatria e Medicina Legal da UFRGS
3. Shear MK, Brown TA, Barlow DH, Money R, Sholomskas DE, Woods SW, et al. Multicenter collaborative panic disorder severity scale. Am J Psychiatry 1997; 154:1571-5. 
Mês/ano:

\begin{tabular}{|c|c|c|c|c|c|c|c|c|c|c|c|c|c|c|c|c|c|c|c|c|c|c|c|c|c|c|c|c|c|c|c|}
\hline & 0 & \begin{tabular}{l|l}
1 & 02 \\
\end{tabular} & 03 & 04 & 05 & 06 & 07 & 08 & 09 & 10 & 11 & 12 & 13 & 14 & 15 & 16 & 17 & 18 & 19 & 20 & 21 & 22 & 23 & 24 & 25 & 26 & 27 & 28 & 29 & 30 & 31 \\
\hline Palpitação & & & & & & & & & & & & & & & & & & & & & & & & & & & & & & & \\
\hline Suor & & & & & & & & & & & & & & & & & & & & & & & & & & & & & & & \\
\hline Falta de ar & & & & & & & & & & & & & & & & & & & & & & & & & & & & & & & \\
\hline Sensação de asfix & & & & & & & & & & & & & & & & & & & & & & & & & & & & & & & \\
\hline Dor torácica & & & & & & & & & & & & & & & & & & & & & & & & & & & & & & & \\
\hline Náusea & & & & & & & & & & & & & & & & & & & & & & & & & & & & & & & \\
\hline $\begin{array}{l}\text { Desconforto } \\
\text { abdominal }\end{array}$ & & & & & & & & & & & & & & & & & & & & & & & & & & & & & & & \\
\hline Atordoação & & & & & & & & & & & & & & & & & & & & & & & & & & & & & & & \\
\hline Desrealização & & & & & & & & & & & & & & & & & & & & & & & & & & & & & & & \\
\hline Despersonalizaç & & & & & & & & & & & & & & & & & & & & & & & & & & & & & & & \\
\hline $\begin{array}{l}\text { Medo de perder } \\
\text { controle }\end{array}$ & & & & & & & & & & & & & & & & & & & & & & & & & & & & & & & \\
\hline Medo de morre & & & & & & & & & & & & & & & & & & & & & & & & & & & & & & & \\
\hline Ondas de calor & & & & & & & & & & & & & & & & & & & & & & & & & & & & & & & \\
\hline Calafrios & & & & & & & & & & & & & & & & & & & & & & & & & & & & & & & \\
\hline Entorpecimento & & & & & & & & & & & & & & & & & & & & & & & & & & & & & & & \\
\hline Formigamento & & & & & & & & & & & & & & & & & & & & & & & & & & & & & & & \\
\hline ISRS (mg/dia) & & & & & & & & & & & & & & & & & & & & & & & & & & & & & & & \\
\hline ADT (mg/dia) & & & & & & & & & & & & & & & & & & & & & & & & & & & & & & & \\
\hline BDZ (mg/dia) & & & & & & & & & & & & & & & & & & & & & & & & & & & & & & & \\
\hline
\end{tabular}

